\title{
Bienestar, familia y problemas de cuidados en América Latina
}

\section{Welfare, family and care Issues in Latin America}

\begin{abstract}
Alejandro H. Del Valle*
Resumen: En este artículo se analizan algunas de las características que poseen los problemas derivados del cuidado y sus relaciones con los regímenes de bienestar en América latina. Para ello se describen los efectos de la transición demográfica, el envejecimiento poblacional, las transformaciones en la familia y la pobreza. A partir de datos provenientes de CEPAL y UNESCO para 16 países latinoamericanos se argumenta que la problemática del cuidado se encuentra en un doble proceso de desfamiliarización y mercantilización. La conclusión a la que se arriba es que las características de los dispositivos estatales y las políticas sociales equiparan a la familia con la mujer por lo que la política implícita del cuidado, en la medida que no se deriva de ningún modelo de justicia social, contribuye a nuevas formas de desigualdad.
\end{abstract}

Palabras clave: Política familiar. Bienestar. Régimen de cuidados. Familia.

Abstract: This article discusses some features that the problems of care have and the relationships with this problems and the welfare regimes in Latin America. For this, Its describe the demographic transition effects, population aging, changes in the family and poverty. Based on data from ECLAC and UNESCO of 16 Latin American countries argued that the problem of care has a double process of defamiliarization and commodification. The paper conclude that the characteristics of the state devices and the social policies system design, woman is equate to family and the regimen has got an implicit policy of care which is not derived from any model of social justice, and developes new forms inequality.

Keywords: Family policy. Welfare. Care regimen. Family.

"Dr. en Sociología -Docente e investigador de la Universidad Nacional de Mar del Plata - Co-fundador de la Red de trabajo en políticas públicas, derechos sociales y trabajo social en el MERCOSUR. E-mail: ajax@datafull.com 


\section{Relaciones entre familia y regímenes de bienestar}

Desde el trabajo de Titmuss (1958) en el que, por medio de establecer un vínculo entre Estado, mercado y familia, distinguió tres modelos de Estado de bienestar ${ }^{1}$ definiéndolos como la "suma de medidas desarrolladas por la sociedad con el fin de enfrentar sus problemas sociales..." (TITMUSS, 1974, p. 47) hasta la tipología elaborada posteriormente por Esping Andersen y su desarrollo a partir del concepto de régimen de bienestar entendido como "los modos en que se reparte la producción de bienestar entre el estado, el mercado y las familias" (ESPING-ANDERSEN, 1999, p. 102) los estudios comparados coinciden en otorgar un lugar privilegiado a la familia como proveedora de bienestar.

Sin entrar en el análisis de las variadas críticas que ha recibido el trabajo de Andersen ${ }^{2}$ podemos afirmar que el bienestar resulta de un complejo institucional que se estructura a partir de los recursos que se obtienen del mercado de trabajo, con prestaciones asociadas con los sistemas de protección social, las políticas sociales y la infraestructura social. Este complejo institucional se sustancia en la esfera doméstica que, a su vez, genera recursos que se distribuyen de manera desigual entre sus miembros. En este sentido, la familia es una institución heterogénea determinada por las diversas estructuras familiares ${ }^{3}$, los ciclos de vida de sus integrantes, y la estabilidad y fluidez de sus relaciones.

En el ámbito de la esfera doméstica podemos distinguir tres elementos que la caracterizan: produce bienes y servicios que no están destinados al intercambio sino al autoconsumo familiar y se realizan en el ámbito privado; el proceso de trabajo depende del control al respecto de las restricciones y los horarios de la

\footnotetext{
1 Los tres modelos eran: el residual, (residual welfare model); el modelo de desempeño industrial (industrial achievement performance model) y el modelo institucional redistributivo (redistributive model).
2 Un desarrollo de las diversas críticas que ha recibido se puede ver en (Del Valle, 2008).

${ }^{3}$ Respecto de las estructuras familiares en la región, destacan las tipologías de Irma Arriagada (1999) (2001) y (2004) que han sido adoptadas en el presente artículo.
}

persona que lo ejecuta bajo el condicionamiento de las necesidades familiares $y$, por último, se remunera a nivel de la subsistencia.

El ámbito de la familia, es decir, de la esfera doméstica, es el ámbito propio de la reproducción de la fuerza de trabajo en el sentido que la fuerza de trabajo no se reproduce en el escenario 'visible' de las mercancías sino que una parte del valor que incorpora resulta del trabajo doméstico. En este proceso de reproducción de la fuerza de trabajo intervienen tres componentes fundamentales: el mercado de trabajo que provee el salario por medio del cual se adquieren bienes y servicios que, a su vez, requieren de alguna elaboración para poder ser consumidos; el trabajo doméstico, que transforma para el consumo los bienes que se adquieren vía el mercado y brinda diversos servicios que no encuentran sustituto o que son poco accesibles por la vía del mercado y, finalmente, los servicios ofrecidos por el Estado.

De hecho, desde su surgimiento los dispositivos estatales de bienestar han cumplido una serie de funciones relacionadas con tareas antes ejecutadas en la esfera doméstica y, de allí que, la familia y la mujer se pueden considerar tanto como pilares del Estado de bienestar como de sus contradicciones. A medida que la familia provee de servicios a sus miembros, los dispositivos de política social inciden sobre las tareas que la familia debe cumplir redefiniendo el trabajo doméstico. Al mismo tiempo, como la asignación de los recursos públicos es heterogénea y desigual, la familia deviene un punto de ensamblaje de recursos y servicios estatales combinados, en muy variadas formas, con los recursos privados.

En América latina, los estudios comparados de los regímenes de bienestar han mostrado avances en la última década ${ }^{4}$. Sabemos que el desarrollo de los regímenes de bienestar en América latina ha sido heterogéneo (DRAIBE; RIESCO, 2005) y que ha estado vinculado al empleo asalariado urbano. En este sentido, los regímenes 'productivistas de bienestar' (DEL VALLE, 2010, p.68-69) privilegiaron una lógica laboral gobernada por el breadwinner

\footnotetext{
${ }^{4}$ Respecto a los diversos trabajos sobre regímenes de bienestar en América latina y sus alcances se puede consultar Del Valle (2010a).
} 
system, en el que la familia y particularmente las mujeres eran las responsables de transferir servicios de cuidados, mientras los hombres adultos desempeñaban el papel de proveedores y portadores de derechos para el resto de la familia a través del empleo formal.

Este sistema, se tradujo en una "... canalización de la protección social principalmente a los trabajadores asalariados de los sectores público y privado y en un fuerte estímulo a la independencia familiar e individual frente al Estado..." (DEL VALLE, 2009, p.31)

También sabemos que en los últimos 30 años se han producido una serie de profundas modificaciones en los sistemas de bienestar latinoamericanos. Por un lado, los procesos de estabilización y reestructuración económica de la región modificaron el entramado de bienestar 'clásico' basado en el empleo y los ingresos.

De este modo, las transformaciones de los mercados laborales; las nuevas orientaciones en política social y los procesos de transición demográfica han modificado profundamente tanto la versión tradicional de familia sobre la que se asentaba el dispositivo estatal de bienestar como a la relación entre Estado- mercado -familia.

Estos cambios se expresan en un mayor número de hogares con jefatura femenina, en el incremento del número de divorcios, en el desempleo y la informalidad; $y$ en un incremento de las tasas de participación y empleo femenino en mercados laborales informales y precarios.

Esta situación modifica la relación entre la estructura social y los dispositivos estatales de bienestar ya que, en la medida que las mujeres ingresan al mercado laboral, envejece la población y cambian los arreglos familiares, entran en tensión los contratos intergeneracionales y de género.

Así, "... Nueva es la mayor demanda de cuidados que genera la irrupción masiva de mujeres que antes eran cuidadoras de tiempo completo en el mercado laboral. Nueva es la mayor inestabilidad de las relaciones conyugales y la incertidumbre que acarrea. Vieja es la debilidad del trabajo para negociar condiciones de remuneración y protección social..." (MARTíNEZ FRANZONI, 2007, p. 1).

En este contexto, la provisión de los servicios de cuidado se transforma en un tema central para el análisis de los procesos de estratificación ya que impacta en las condiciones de vida de la población y junto con los cambios en la estructura de edad como en la familia ejercen presión tanto sobre el Estado como la familia y el mercado y en el proceso de interacción entre ellos.

\section{El concepto de cuidado}

El concepto de cuidado sirve para relacionar múltiples dimensiones del desarrollo y el bienestar social que abarcan desde los derechos humanos, la protección social hasta las desigualdades de género y socioeconómicas.

Tanto el problema del cuidado como el del trabajo no remunerado en general, en América latina, poseen características que lo diferencian con lo que ocurre en los regímenes clásicos de bienestar elaborados por Esping Andersen y configuran las características principales de la economía política del desarrollo en América latina.

En el 2009, la CEPAL afirmaba que: “....Los marcos normativos de los países de la región, así como el abanico de programas sociales existentes relacionados con la protección de la infancia y la vejez y con la dependencia revelan una creciente concentración en la familia de los riesgos asociados con el cuidado..." (CEPAL, 2009, p. 228)

En este sentido, el cuidado hace evidente los límites de los sistemas de bienestar latinoamericanos, en la medida que, estas actividades recaen sobre uno de los aspectos y situaciones de la vida humana donde las desigualdades, económicas, sociales, de género, se materializan en situaciones concretas.

En primer lugar, las desigualdades económicas segmentan el acceso a los servicios de cuidado que brinda el mercado y acentúan los procesos de estratificación del bienestar. Por otra parte, las desigualdades sociales, como resultado de los procesos de estratificación profundizan las brechas entre clases sociales y en las redes de apoyo dificultando el mantenimiento o la mejora del bienestar; finalmente, esta dificultad conduce a una mayor sobrecarga femenina en las labores de cuidado ya que, la división sexual del trabajo de cuidado continua recayendo en las mujeres.

Los diversos análisis teóricos sobre el cuidado han resaltado la importancia del cuidado como una relación caracterizada por la interconexión y la interdependencia 
(GILLIGAN, 1982; BUBECK, 1995). En este sentido, la práctica del cuidado contrasta con el comportamiento basado en la racionalidad económica y con la idea de que la esfera privada de la familia es el lugar que ha de proveer socorro a aquellos que han sido excluidos de las relaciones competitivas del mercado.

De hecho, los estudios de género han mostrado que la separación entre público y privado se ha originado en una división del trabajo basada en el género y en la noción de trabajo asalariado y trabajo no asalariado. En los estudios feministas pioneros sobre políticas sociales se ha argumentado que el ingreso de la mujer en la provisión de servicios de bienestar como por ejemplo, guarderías, escuelas, hospitales y geriátricos, representa una forma de 'patriarcado público' (SIIM, 1987).

En el presente trabajo, nos interesa utilizar el concepto de cuidado como herramienta analítica con el fin de analizar los regímenes de bienestar en América latina ya que asumimos que éste concepto nos facilitará la comprensión de diversas características de los acuerdos societales en torno a las necesidades personales y de bienestar de los ciudadanos.

Nos interesa analizar el cuidado en términos sociales y no en su dimensión individual. En este punto, el cuidado posee tres dimensiones fundamentales: la primera se refiere a la noción de cuidado como actividad rentada, es decir, como trabajo que se desarrolla bajo ciertas condiciones, asalariada o no asalariadamente; formal o informalmente y en función de una política estatal que condiciona el desarrollo de cada dimensión. La segunda dimensión, se vincula a la idea del cuidado como ideal normativo, es decir, como obligación y responsabilidad. Esta dimensión normativa del cuidado deja al descubierto las relaciones sociales sobre las que se desenvuelve y el rol del estado en el fortalecimiento y/o debilitamiento de las normas existentes sobre el mismo. Por último, el cuidado, como actividad social que comporta costos financieros y emocionales y se desenvuelve en las aristas de lo público y lo privado.

El cuidado, en términos sociales, puede ser definido como las actividades y relaciones que se desarrollan con el fin de satisfacer las necesidades físicas y emocionales de adultos, niños y de aquellos que no se pueden auto sostenerse e incluye el marco normativo, económico y social en el que las mismas son asignadas y llevadas adelante.

A diferencia de otras áreas del bienestar que, como el seguro social, es provisto por el Estado; en la provisión de servicios de cuidado pueden intervenir cuatro sectores: la familia, el Estado, el mercado o el voluntariado (tercer sector).

Cada uno de éstos se caracteriza por diferentes modos de regulación: la familia se regula en base a principios recíprocos de solidaridad; el mercado, por relaciones competitivas basadas en la búsqueda de beneficios económicos; el Estado, por el ordenamiento jerárquicos y principios normativos de derecho y; el tercer sector, por valores basados en la solidaridad y el voluntariado.

No obstante, para que cada uno de estos sectores pueda proveer a las necesidades del cuidado tienen que existir ciertas condiciones. Por ejemplo, las familias deben contar con ingresos y recursos suficientes provistos por los miembros adultos (aquí se incluye el tiempo y los afectos) $y$, al mismo tiempo tienen que existir vínculos de estabilidad y cooperación entre sus miembros; las comunidades, a su vez, han de contar con vínculos basados en formas básicas de reciprocidad y confianza que permitan establecer relaciones dinámicas de cooperación; el mercado, ha de tener que conseguir algún potencial beneficio económico asociado a la provisión de servicios de cuidado; por último, el Estado puede orientar tanto la calidad como la modalidad de la provisión de servicios de cuidado por medio de la provisión pública y la regulación legal.

Sin duda, los dispositivos de intervención estatal en el área inciden en las formas en que las familias, el mercado o las asociaciones comunitarias participan o no en la provisión de cuidados y en el modo en que se redistribuyen las responsabilidades y la capacidad que posee cada sector para la efectiva provisión de estos servicios.

Con el objetivo de analizar la distribución de los cuidados, éstos pueden clasificarse en tres tipos según hacia quien está orientado: el cuidado proporcionado a niños, niñas y adolescentes; el cuidado que se dedica a la atención para hacer frente a una enfermedad, crónica o aguda, llamado cuidado asistencial (MURILLO, 2003) y el cuidado hacia las personas mayores.

En el primero de estos tipos de cuidado no existe una clara frontera entre las actividades 
de cuidado y las actividades propias del proceso de formación y educación inicial. En el caso de las personas mayores dependientes existen también dificultades para que las tareas que integran el cuidado sean reconocidas como tales cuando son prestadas de manera informal. En parte esto responde a que "...el cuidado está inmerso en la lógica del sacrificio, un sacrificio que puede entrañar -sin pretenderlo- un grado de reconocimiento social. A pesar de que la enfermedad se cronifique, y ésta termine por saquear el tiempo a quien lo prodiga. La filantropía, la entrega, emparentada con la caridad, están imbricadas en el simbolismo del espacio público que les fue concedido a las mujeres. E incluso, su relación con la honestidad de la mujer. A diferencia del sufragio universal, la filantropía podría considerarse como una presencia consentida de las mujeres en el espacio público..." (MURILLO, 2003, p. 6-7).

\section{Cuidado social y efectos de la transición demográfica}

En América latina, las necesidades derivadas del cuidado han crecido sustancialmente debido a los cambios de edad de la población y a las transformaciones de las estructuras familiares. Por un lado, el principal proveedor de cuidados, la familia, actualmente encuentra severas limitaciones en su capacidad para movilizar recursos y los estados, a su vez, se encuentran limitados bajo presiones financieras como políticas.

Al mismo tiempo, la transición demográfica ${ }^{5}$ presenta una tendencia a la disminución de la proporción entre niños(as) y mujeres que influye en la en la carga de trabajo reproductivo de las mujeres. Paralelamente, presenta una tendencia al incremento en la proporción de personas adultas mayores respecto a la de mujeres en edad económicamente activa (Cuadro $n^{\circ} 1$ ). De este modo, se puede afirmar que las cargas de trabajo femenino de cuidado de niños(as) asociadas a la configuración de la estructura demográfica poseen una relación inversamente proporcional al nivel de avance en el proceso de transición demográfica mientras que las cargas asociadas con el cuidado de personas adultas mayores son directamente proporcionales al proceso.

Cuadro 1. América Latina (20 países): clasificación según su ubicación en la Tasa de Niños(as) por Mujer Activa y la Tasa de Adultos(as) Mayores por Mujer Activa

\begin{tabular}{|c|c|c|c|c|c|c|}
\hline & \multicolumn{6}{|c|}{ Tasa de niños(as) por mujer activa } \\
\hline \multirow{6}{*}{ 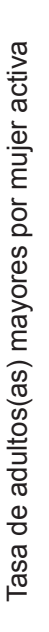 } & & Alta & Media - Alta & Media & Media - Baja & Baja \\
\hline & Alta & & & & Uruguay & $\begin{array}{c}\text { Argentina } \\
\text { Cuba }\end{array}$ \\
\hline & Media - Alta & & & & & \\
\hline & Media & & & & Chile & \\
\hline & Media - Baja & & $\begin{array}{c}\text { Rep. Dominicana } \\
\text { Ecuador }\end{array}$ & $\begin{array}{c}\text { Perú } \\
\text { México } \\
\text { Panamá }\end{array}$ & Costa Rica & \\
\hline & Baja & $\begin{array}{c}\text { Nicaragua } \\
\text { Honduras } \\
\text { Haití } \\
\text { Guatemala } \\
\text { Bolivia } \\
\text { Paraguay }\end{array}$ & El Salvador & $\begin{array}{c}\text { Brasil } \\
\text { Colombia } \\
\text { Venezuela }\end{array}$ & & \\
\hline
\end{tabular}

Fuente: Elaboración propia con base en datos del Centro Latinoamericano y Caribeño de Demografía (CELADE) de la Comisión Económica para América Latina y el Caribe (CEPAL). Disponibles en: <http://www.eclac.cl/celade/proyecciones/basedatos_BD.htm>.

\footnotetext{
${ }^{5}$ La transición demográfica ha sido descrita como un proceso de larga duración, que transcurre entre dos situaciones o regímenes extremos: uno, inicial, de bajo crecimiento demográfico con altas tasas de mortalidad y fecundidad, y otro, final, de bajo crecimiento pero con niveles bajos en ambas tasas. Entre ambas situaciones se pueden identificar dos momentos principales. El primero, en el que la tasa de crecimiento de la población aumenta como consecuencia del descenso de la mortalidad, y el segundo, en el que dicho crecimiento disminuye, debido al descenso posterior de la fecundidad. En qué magnitud y a que velocidad cambia la tasa de crecimiento, dependerá de la velocidad y del momento en que comienzan a descender la mortalidad y la fecundidad (CHESNAIS, 1986).
} 
Para mostrar esta tendencia, en el cuadro 2 se encuentran agrupados los países latinoamericanos en cuatro categorías que muestran su posición relativa en una escala de transición demográfica: de personas dependientes que soportan las personas adultas en edad económicamente activa pueden traducirse en una reducción de las tensiones entre los trabajos productivos

Cuadro 2. Distribución de los países de América Latina por grupos de transición demográfica (CELADE/BID, 1996)

\begin{tabular}{|c|c|}
\hline Clases de Transición Demográfica: Definición CELADE & Países \\
\hline $\begin{array}{l}\text { Grupo I. Transición incipiente. } \\
\text { Países con alta natalidad y mortalidad, con un crecimiento natural moderado, del orden de } 2.5 \% \text {. } \\
\text { Los países de este grupo tienen una estructura por edades muy joven y una alta relación de } \\
\text { dependencia. }\end{array}$ & Bolivia y Haití \\
\hline $\begin{array}{l}\text { Grupo II. Transición moderada. } \\
\text { Países de alta natalidad pero de nivel moderado de mortalidad. Por este motivo su crecimiento } \\
\text { natural es todavía elevado, cercano al } 3 \% \text {. El descenso de la mortalidad, sobre todo durante el } \\
\text { primer año de vida, se ha traducido en un rejuvenecimiento de la estructura por edades, lo que } \\
\text { también lleva a una elevada relación de dependencia. }\end{array}$ & $\begin{array}{l}\text { El Salvador, Guatemala, Honduras, } \\
\text { Nicaragua y Paraguay }\end{array}$ \\
\hline $\begin{array}{l}\text { Grupo III. En plena transición. } \\
\text { Países con natalidad moderada y mortalidad moderada o baja, lo que determina un crecimiento } \\
\text { natural moderado cercano al } 2 \% \text {. Como el descenso de la fecundidad es reciente la estructura } \\
\text { por edades se mantiene todavía relativamente joven, aún cuando ya ha disminuido la relación } \\
\text { de dependencia. }\end{array}$ & $\begin{array}{l}\text { Brasil, Colombia, Costa Rica, } \\
\text { Ecuador, México, Panamá, Perú, } \\
\text { República Dominicana, Venezuela. }\end{array}$ \\
\hline $\begin{array}{l}\text { Grupo IV. Transición avanzada. } \\
\text { Países con bajas tasas de natalidad y bajas o moderadas tasas de mortalidad, lo que se traduce } \\
\text { en un crecimiento natural bajo, del orden del } 1 \% \text {. } \\
\text { Dos subgrupos se distinguen: } \\
\text { Países que han tenido fecundidad y mortalidad bajas por un largo período (Argentina, Uruguay } \\
\text { y, en menor medida, Cuba) y que, por lo tanto, tienen un crecimiento y una estructura de edades } \\
\text { similares a los de países desarrollados; } \\
\text { Países que, si bien recientemente han alcanzado tasas muy bajas de fecundidad y mortalidad, } \\
\text { tienen aún tasas de crecimiento más elevadas debido a su población relativamente joven. }\end{array}$ & Argentina, Chile, Cuba y Uruguay. \\
\hline
\end{tabular}

Fuente: CELADE, 1992; CELADE/BID, 1996. Para el cálculo de las etapas de la transición demográfica, CELADE considera las tasas brutas de natalidad y mortalidad, que determinan el crecimiento vegetativo y la estructura por edades de la población (CELADE/BID, 1996).

En este sentido, se observa que los países con cargas altas en el cuidado de niños(as) poseen baja carga de cuidado de personas adultas mayores y pertenecen a los grupos I y II (Nicaragua, Honduras, Haití, Nicaragua, Bolivia y Paraguay) mientras que las bajas cargas de cuidado de niños(as) y las cargas altas de cuidado de personas mayores corresponden a los países del grupo IV (Argentina, Cuba y Uruguay Chile). Finalmente, en un tercer grupo (Venezuela, Panamá, Perú, México, Colombia y Brasil) la transición demográfica ha reducido la carga de cuidado infantil a un nivel medio, mientras que la de cuidado de personas mayores es aún relativamente baja.

Así, los efectos combinados del aumento de la esperanza de vida y la disminución de la fecundidad provocan que la tasa de dependencia demográfica tienda a incrementarse, estabilizarse o descender ${ }^{6}$. Los descensos en la carga y reproductivos. En el ámbito productivo, las menores exigencias de generación de ingresos familiares asociadas con menos personas dependientes pueden implicar una mayor holgura para prolongar la etapa de instrucción formal de mujeres y hombres, y para acceder a trabajos de mejor calidad. En el ámbito reproductivo, la disminución de la carga de trabajo de cuidado de personas dependientes también favorece la inserción laboral y las actividades de instrucción y capacitación de las mujeres.

Los procesos de estratificación también tienen consecuencias en los procesos de

\footnotetext{
6 La tasa de dependencia demográfica es la relación entre personas menores de 15 años y mayores de 64 años con respecto a la cantidad de personas económicamente activas. Al margen de las limitaciones que presenta este indicador (UTHOFF, VERA; RUEDI, 2006) es útil para una aproximación al potencial de ingresos para la subsistencia de las familias.
} 
transición demográfica en los diferentes grupos de población de la región con las consiguientes necesidades de cuidado. Al respecto, existen diferencias entre estratos de ingreso, grupos étnicos y grupos de edad, al respecto, Rodríguez Vignoli (2004) utilizando como variable el nivel de instrucción para identificar indirectamente los distintos niveles de ingreso ha indicado que los estratos de ingresos bajos, identificados por medio de las mujeres sin instrucción o con nivel de instrucción primaria, experimentan mayores tasas de fecundidad que los de ingresos medios 0 altos.

Con respecto a las diferencias por grupo de edad, luego de analizar 7 países latinoamericanos (Bolivia, Costa Rica, Ecuador, México, Panamá y Uruguay), Rodríguez Vignoli (2004) muestra que en todos ellos la alta fecundidad adolescente está concentrada en el estrato de bajos ingresos y no baja de $17 \%$ mientras que en los estratos altos es marginal.

La alta fecundidad adolescente se vincula a los bajos niveles de instrucción o solo con instrucción básica y llega al $40 \%$ en Nicaragua y Panamá. Asimismo, se constata una baja sustancial de ese indicador cuando las adolescentes culminan la educación secundaria; de hecho, la diferencia porcentual entre la alta fecundidad de adolescentes con educación secundaria y la de aquellas que tienen solamente educación básica oscila entre el 80\% (Uruguay) y el $40 \%$ (México).

Así, la probabilidad de experimentar fecundidad alta se ha reducido de forma generalizada y en los rangos de edad de las mujeres entre 15 y 40 años, con la excepción del rango comprendido entre 15 y 17 años, en el cual la alta fecundidad tiende a aumentar CEPAL (2008) y se concentra en el estrato de bajos ingresos y bajo nivel educativo. A esta situación, adicionalmente, hay que considerar que en América latina la población indígena y afro descendiente es la más pobre, con menor nivel educativo y se concentra en empleos precarios y mal remunerados por lo que la situación tiende a concentrarse en estos grupos.

\section{Estructuras familiares y demanda de cuidado}

Los efectos de la transición demográfica en los hogares se han traducido en una reducción del tamaño promedio y, por tanto, de la carga de cuidado de dependientes en su interior. Arriagada (2004), comparando el número promedio de miembros de familias urbanas en 13 países, entre fines de los 80 y fines de los 90 observó una disminución del tamaño promedio de la familia.

En los países con transiciones demográficas más avanzadas las familias promedio son más pequeñas; tales son los casos de Uruguay y Argentina, con tamaños promedio ligeramente superiores a 3 miembros. En el otro extremo se encuentran los países más rezagados en la transición demográfica, como Guatemala, Honduras y Nicaragua; sus familias promedio tienen casi 5 miembros, "...Esta tendencia se registra en todos los países latinoamericanos, aunque con variaciones significativas. Uruguay es el que registra el menor tamaño promedio por hogar (tres personas en 2005) mientras que Nicaragua se sitúa en el extremo opuesto (5.1 personas en 2001)..." (ARRIAGADA, 2007, p.14).

Otros de los cambios que se ha constatado en la región es el "incremento de los hogares con jefatura femenina y la creciente participación de las mujeres en el mercado laboral" (SUNKEL, 2006, p.16). En términos de las estructuras familiares se ha hablado de la diversificación “...El modelo más importante de familia nuclear, la biparental con hijos, se redujo (de 46.3 por ciento en 1990 a 41.1 por ciento en 2005). Este modelo coexiste con la familia extendida de tres generaciones (en 2005 algo más de un quinto de todas las familias urbanas latinoamericanas, 21.7 por ciento), las familias nucleares mono-parentales, principalmente a cargo de mujeres (12.2 por ciento en 2005), los hogares unipersonales (9.7 por ciento en 2005), las familias nucleares sin hijos, los hogares sin núcleo conyugal y las familias compuestas (ARRIAGADA, 2007, p.10).

Aún cuando persiste la cultura patriarcal: en 2002, por ejemplo, tan sólo $36 \%$ de las familias se ajustaban al modelo tradicional de la familia nuclear con un proveedor y en 2005 , sólo el 20.9 \% (ARRIAGADA, 2007, p.12); en las áreas urbanas un $19 \%$ de las familias nucleares son mono-parentales, de las cuales un $84 \%$ tenían de jefatura femenina y un $16 \%$ de jefatura 
masculina (ARRIAGADA, 2004; SCHKOLNIK, 2004).

En otras palabras, el modelo de hombre proveedor se ha alterado: ha aumentado la proporción de familias bi-parentales con hijos, donde ambos padres desarrollan actividades remuneradas (de $27 \%$ a $33 \%$ ), acompañado del aumento de la proporción de familias nucleares mono-parentales, de las familias nucleares con jefas que trabajan, de las familias de jefatura masculina ${ }^{7}$ (ARRIAGADA, 2004) y de las uniones de consenso (RODRÍGUEZ VIGNOLI, 2004).

Paradójicamente, el trabajo doméstico no remunerado sigue siendo realizado predominantemente por la mujer, en las distintas estructuras familiares (ARRIAGADA, 2004) debido a que los cambios en las estructuras familiares y principalmente en la división sexual del trabajo son, como en otras partes, lentos, culturalmente arraigados y no reflejan de modo alguno el nivel desarrollo económico ${ }^{8}$.

En este sentido, es importante destacar que la tasa de dependencia es directamente proporcional a la cantidad de miembros del hogar por lo que la carga de cuidado de dependientes tiende a ser mayor en los países más rezagados en la transición demográfica, que a la vez, son los que poseen menores opciones de derivar esa responsabilidad hacia servicios brindados por el estado o el mercado y, al mismo tiempo, la carga de dependencia tiende a concentrarse más en los hogares de menores ingresos (Cuadro 3).

\footnotetext{
${ }^{7}$ Informaciones presentadas por la autora indican que, en Buenos Aires, la proporción de familias del tipo hombre-proveedor bajó de $74,5 \%$ a $54,7 \%$ entre 1980 y 2000 , mientras la participación de familias con dos proveedores aumentó de $25,5 \%$ a $45,3 \%$. En ciertos países, como Perú y Ecuador, el aumento de familias de jefatura masculina coincide con el aumento de las migraciones femeninas (ARRIAGADA, 2004).

${ }^{8}$ Uruguay registra a la vez uno de los más que altos niveles de PIB por habitante y un porcentaje de cónyuges que trabajan de forma remunerada $(52 \%)$ superior a las que permanecen en el hogar (29\%), sin embargo en Chile, Costa Rica, Honduras, México y Argentina el porcentaje de mujeres cónyuges en actividades domésticas aún supera al de cónyuges en el mercado del trabajo (SCHOLNICK, 2004).
}

Cuadro 3. Tamaño medio de las familias urbanas según tipo y quintil de ingresos, alrededor del 2002 (Número de personas)

\begin{tabular}{|c|c|c|c|c|c|}
\hline & \multicolumn{5}{|c|}{ Media (1) } \\
\hline & Q I & Q II & Q III & Q IV & Q V \\
\hline Guatemala & 6,2 & 5,2 & 4,7 & 4,1 & 3,5 \\
\hline Nicaragua & 5,9 & 5,7 & 5,1 & 4,7 & 4 \\
\hline Honduras & 5,5 & 5,1 & 4,7 & 4,2 & 3,6 \\
\hline Venezuela & 5 & 5 & 4,5 & 4,1 & 3,5 \\
\hline Ecuador & 4,9 & 4,5 & 4,2 & 3,8 & 2,9 \\
\hline Bolivia & 5,3 & 4,8 & 4,1 & 4,1 & 3,2 \\
\hline EI Salvador & 4,7 & 4,4 & 4,2 & 3,7 & 3,3 \\
\hline R. Dominicana & 4,2 & 4,1 & 4 & 3,6 & 3,3 \\
\hline Colombia & 4,5 & 4,5 & 4,2 & 3,7 & 3 \\
\hline México & 6 & 5,6 & 4,7 & 4,3 & 3,4 \\
\hline Panamá & 4,6 & 4,4 & 4 & 3,5 & 3 \\
\hline Costa Rica & 4,3 & 4,2 & 4,1 & 3,6 & 3,1 \\
\hline Chile & 4,7 & 4,3 & 3,8 & 3,3 & 3 \\
\hline Brasil & 4,5 & 4 & 3,3 & 3,2 & 2,8 \\
\hline Argentina & 4,8 & 3,6 & 2,9 & 2,8 & 2,7 \\
\hline Uruguay & 4,6 & 3,4 & 2,8 & 2,4 & 2,1 \\
\hline
\end{tabular}

Fuente: CEPAL, sobre la base de tabulaciones especiales de las encuestas de hogares de los respectivos países.

Nota (1) En la media del tamaño de las familias según quintil se consideran los hogares unipersonales.

Otro fenómeno que indica transformación en curso es la relación que existe entre envejecimiento poblacional y la proporción de hogares con personas mayores. Si bien, la responsabilidad de cuidado de personas mayores implica oportunidades por los ingresos que esas personas puedan aportar y los servicios de cuidado de menores de edad y de trabajo doméstico que puedan brindar existen riesgos relacionados con los costos familiares asociados a la atención de las personas mayores y el tiempo que deben invertir otros miembros del hogar para cuidarles.

En este sentido, la reducción de los hogares familiares y el incremento de los hogares unipersonales podrían estar indicando la pérdida de capacidad de la estructura de los hogares para asumir trabajo reproductivo vinculado al cuidado de los adultos mayores. Por lo que las nuevas demandas de cuidado y las transformaciones en las estructuras familiares, se transformarían en la fuente de una serie de tensiones. Por un lado, las familias biparentales con hijos y las extendidas, en teoría, serían las que tendrían mayor capacidad de efectuar trabajo reproductivo; las primeras porque constituyen el típico modelo de hogar. A su vez, en América Latina la familia extendida tiene mayor capacidad de absorción de trabajos reproductivos que la biparental, pues 
mantiene la estructura de relaciones familiares propia del hogar nuclear con la posibilidad de que otros familiares contribuyan con las tareas domésticas y con el aporte de ingresos. Sin embargo, la participación relativa de ambos tipos de hogar se redujo de $69,3 \%$ a $65,6 \%$ entre 1990 y el 2002 (cuadro 4).

Esta tendencia apunta hacia una reducción en la capacidad de ejecución de trabajos reproductivos de la estructura familiar de los países latinoamericanos. Las dificultades para conciliar las responsabilidades familiares y laborales son mayores en los hogares con mayor capacidad de absorber trabajo reproductivo: los biparentales con hijos(as) y extendidos, en la medida en que crece la incorporación de las mujeres que los integran a las actividades remuneradas. sociales particularmente altas. Casualmente, los hogares mono-parentales son el único tipo de hogar familiar que ha aumentado su peso relativo dentro del conjunto de hogares familiares, pues el otro tipo de familia que ha crecido relativamente es el de los hogares biparentales sin hijos(as) dando lugar a una transferencia de carga de cuidado de dependientes de los hogares dirigidos por parejas -los biparentales con hijos(as) y los extendidos- hacia los mono-parentales con jefatura femenina, que son en su gran mayoría de los mono-parentales.

Es decir, están creciendo en la región las vulnerabilidades inherentes al cuidado de dependientes y éstas afectan tanto a las personas que ejercen esa función de cuidados como a los(as) niños(as), las personas mayores y las discapacitadas.

Cuadro 4. América Latina distribución porcentual de los hogares según tipo, 1990 y 2002

\begin{tabular}{|c|c|c|c|c|c|c|c|c|}
\hline & $\begin{array}{c}\text { Hogar } \\
\text { unipersonal }\end{array}$ & $\begin{array}{c}\text { Hogar sin } \\
\text { núcleo } \\
\text { conyugal }\end{array}$ & $\begin{array}{c}\text { Nuclear } \\
\text { biparental sin } \\
\text { hijos }\end{array}$ & $\begin{array}{c}\text { Nuclear } \\
\text { biparental con } \\
\text { hijos }\end{array}$ & $\begin{array}{c}\text { Nuclear mono- } \\
\text { parental jefe } \\
\text { hombre }\end{array}$ & $\begin{array}{c}\text { Nuclear } \\
\text { mono- } \\
\text { parental jefe } \\
\text { mujer }\end{array}$ & Extendida & Compuesta \\
\hline 1990 & 6.7 & 4.8 & 7.2 & 46.3 & 1.3 & 8.4 & 23 & 2.4 \\
\hline 2002 & 8.4 & 4.8 & 7.7 & 42.8 & 1.5 & 9.8 & 22.8 & 2.1 \\
\hline
\end{tabular}

Fuente: CEPAL, sobre la base de tabulaciones especiales de las encuestas de hogares de los respectivos países.

Nota (1) En la media del tamaño de las familias según quintil se consideran los hogares unipersonales.

La afirmación precedente es consecuente con los resultados de CEPAL (2007a) que, sobre 15 países de la región, ha indicado que tanto en las zonas urbanas como en las rurales los porcentajes de hogares biparentales y extendidos y compuestos donde la mujer es la principal contribuyente de ingresos tendían a incrementarse variando entre el 15\% (México, Chile y Bolivia) y el $24 \%$ (El Salvador) en los hogares biparentales; mientras que en los hogares extendidos y compuestos esos porcentajes oscilaban entre el 35\% (Chile y Ecuador) y el $49 \%$ (El Salvador). De este modo, la presencia de la mujer como sustentadora principal del hogar es un fenómeno que crece y que, sumado a la tradicional división sexual del trabajo hace prever un incremento en los déficits de cuidados.

En la misma dirección se está produciendo el crecimiento de los hogares mono-parentales con jefatura femenina. En este caso, las estrategias para conciliar las tareas domésticas y de generación de ingresos entrañan vulnerabilidades

\section{Bienestar y provisión de cuidados}

Tradicionalmente, los regímenes de bienestar en América Latina han sido productivistas y "privilegiaron al trabajador ocupado formalmente. Esto se tradujo en una canalización de la protección social principalmente a los trabajadores asalariados de los sectores público y privado y en un fuerte estímulo a la independencia familiar e individual frente al Estado..." (DEL VALLE, 2010, p.68).

Los principales dispositivos de intervención estatal en política social fueron, en ese escenario el empleo y los ingresos ya que, la condición "... de trabajador operaba como garantía de acceso a los derechos y beneficios sociales y es la base de la política redistributiva o de garantías sociales que era implementado mediante asignaciones familiares o seguros sociales..." (SUNKEL, 2006, p.26).

El seguro social (pensiones de vejez e invalidez, seguros de desempleo, de salud, accidentes, de maternidad, etc.) -fue el principal dispositivo estatal de bienestar. Éste se financiaba 
con el aporte del trabajador/a, el empleador/a y el Estado con una concepción solidaria. Este sistema se complementaba con dispositivos de asistencia social (servicios para superar la pobreza de grupos carentes de recursos, preferentemente programas tendientes a promover el pleno empleo o empleo temporal, programas de alimentación-nutrición, salud) destinados a los sectores que no tenían un empleo formal; por último existían las subvenciones sociales (subsidios familiares para la vivienda, educación).

Estos dispositivos presuponen un modelo de seguridad familiar donde, a través de la reproducción de ciertos roles de género, deja a las mujeres a cargo del cuidado familiar y acceden a la seguridad social de manera indirecta por medio de la inserción laboral del marido.

En ese contexto, la familia era la principal encargada de proveer los cuidados y, por ello, la provisión pública de servicios en esta área ha tenido escaso desarrollo.

En la actualidad, como ha señalado Batthyány (2006, p.129): “...El Estado focaliza sus prestaciones hacia los sectores de menores recursos económicos; los sectores más favorecidos económicamente recurren a la compra de servicios en el mercado y los sectores medios probablemente desarrollen estrategias más vinculadas a las redes familiares y comunitarias. En todos los casos, sin embargo, los cuidados infantiles dependen de una compleja ambivalencia de prestaciones familiares, domésticas, estatales, remuneradas y no remuneradas...".

En lo referido al cuidado en la infancia, CEPAL (2009, p.45) ha indicado que el Estado puede proveer servicios de cuidado a la infancia mediante educación preescolar y tiempo extendido escolar. Sin embargo, tanto las reducidas jornadas en la escuela como la exclusión del sistema educativo de niños menores de seis años han sido, hasta el presente un dato insoslayable de la realidad de nuestro continente. Esta situación es coherente con el presupuesto de que en los hogares existían cuidadores de tiempo completo, sobre todo mujeres que asumían las tareas de reproducción para los más pequeños y para los niños fuera de la jornada escolar.
En este sentido, los dispositivos de intervención estatal destinados al cuidado de niños se orientan a poblaciones con rasgos específicos y se centra en "...la salud física y la prevención de enfermedades, por una parte, y la alimentación y la nutrición por la otra..." (CEPAL, 2009, p.235), esta situación se corresponde con los resultados obtenidos por Batthyány (2007).

En este sentido, los servicios públicos de cuidado infantil son de baja cobertura. En el Cuadro 5, se puede observar que a excepción de Guatemala todos los países tienden al incremento de la matriculación preescolar y, conjuntamente también al incremento de la provisión privada de este servicio por lo que tenemos dos procesos que coexisten.

Por un lado, una baja cobertura pública y un incremento de la demanda y, por otro una creciente tendencia a la mercantilización del mismo con el consiguiente impacto en los procesos de segmentación.

“...En la mayoría de los países, la principal oferta en cuanto a jornada extendida y de mejor calidad es privada y su cobertura depende de la capacidad de pago de las familias, con la segmentación social que ello supone. Además, la tasa de asistencia a los programas de cuidado y educación preescolar es más elevada en las zonas urbanas. Este es un factor de reproducción de la desigualdad debido a que, tal como muestra la profusa evidencia empírica internacional, los niños de medios sociales más desfavorecidos son quienes más necesitan programas de educación temprana (OIT/PNUD, 2009)..." (CEPAL, 2009, p.230).

La jornada extendida presenta importantes alcances en lo que respecta a la disminución de la tensión intrafamiliar ya que alivia la preocupación por el cuidado extraescolar, incluida la alimentación y facilita la incorporación de las madres al mercado laboral. En el caso de la población más vulnerable, la permanencia de los niños y niñas en la escuela disminuye las probabilidades de que se sometan a diversos tipos de riesgos externos contribuyendo al mejoramiento de la vida familiar al existir mayor seguridad y confianza en las actividades que realizan los hijos (CEPAL, 2009a). 
Cuadro 5. Tasa neta de matriculación preescolar y porcentaje de matrícula privada 2001/2007. En porcentajes sobre el total de la población en edad de matricularse

\begin{tabular}{|c|c|c|c|c|}
\hline & \multicolumn{2}{|c|}{$\begin{array}{c}\text { Tasa neta de } \\
\text { matriculación }\end{array}$} & \multicolumn{2}{c|}{$\begin{array}{c}\text { Porcentaje de } \\
\text { matrícula privada }\end{array}$} \\
\hline & 2001 & 2007 & 2001 & 2007 \\
\hline Argentina & 60,65 & 68,31 & 28,21 & 30,89 \\
\hline Bolivia & 36,38 & 39,75 & 24,24 & 10,43 \\
\hline Brasil & 50,28 & 48,55 & 28,67 & 24,45 \\
\hline Chile & & 52,82 & (a) 46,55 & 55,56 \\
\hline Colombia & 35,65 & 33,69 & 40,53 & 40,97 \\
\hline Costa Rica & & & 14,67 & 13,41 \\
\hline R. Dominicana & 26,66 & 28,88 & 38,3 & 52,45 \\
\hline Ecuador & 58,6 & 83,33 & 41,04 & 38,92 \\
\hline El Salvador & 41,17 & 49,09 & 20,56 & 19,03 \\
\hline Guatemala & 40,91 & 27,25 & 19,27 & 20 \\
\hline Honduras & 21,91 & 31,47 & (b) 22,91 & $($ c) 13,16 \\
\hline México & 67,4 & 96,87 & 10,02 & 15,23 \\
\hline Nicaragua & 28,28 & 54,1 & 16,82 & 15,61 \\
\hline Panamá & 48,81 & 61,35 & 19,27 & 15,87 \\
\hline Paraguay & (d)29,94 & 31,2 & 28,51 & 29,69 \\
\hline Perú & 59,26 & 64,22 & 15,51 & 23,64 \\
\hline Uruguay & (d) 58,39 & 72,23 & 18,05 & 43,3 \\
\hline Venezuela & 46,12 & 55,07 & 18,69 & 20,08 \\
\hline
\end{tabular}

Fuente: Elaboración propia en base a UNESCO.

(a) 2002; (b) 2005; (c) 2008; (d) 2004

A pesar de esto, la educación preescolar en general no es obligatoria y son las familias quienes deciden el tipo de cuidado al que acceden sus hijos e hijas. Los servicios para los más pequeños sólo están dirigidos a los sectores más pobres de la población, en general con niveles bajos de cobertura. Al mismo tiempo se está desarrollando una creciente mercantilización del cuidado infantil para los sectores sociales que pueden pagarlos. Así, el problema no reside tanto en la universalización de los servicios de cuidado sino en la creciente segmentación del sistema que estaría indicando una profunda transformación aún en los sistemas más incorporantes.

En términos generales, los programas específicos a la niñez se orientan al reconocimiento y restitución de los derechos de niños y niñas (Bolivia, Chile, Colombia, Cuba, Honduras, Perú y República Dominicana ${ }^{9}$ ). En este sentido,

9 En República Dominicana, se ha creado el Consejo Nacional de Estancias Infantiles (CONDEI) que ofrece hogares de paso y programas de apoyo a menores abusados y víctimas de explotación. existen programas de intervención y protección social y modalidades de hogares sustitutos y casas de protección a los niños y niñas en grave riesgo o peligro (Hogares gestores en Colombia, por ejemplo).

Nos encontramos frente a dos procesos respecto al cuidado de los niños. Por un lado, en los estratos de medios y altos ingresos asistimos a la mercantilización mientras que en los quintiles más bajos, los cuidados recaen en la "solidaridad familiar", situación que representa una gran sobrecarga para las mujeres en la medida que se carece de una adecuada cobertura para la atención de los niños.

En relación al cuidado de los adultos mayores, como se dijo, los procesos de transición demográfica afectan diferencialmente a los países latinoamericanos. El aumento de la proporción de las personas mayores de 65 años alcanzan el $9.8 \%$ de la población total en Argentina, el $7.2 \%$ en Chile y el $12.9 \%$ en Uruguay lo que conlleva al incremento de los gastos sanitarios y asistenciales y el creciente peso de las personas no incluidas en el sistema de seguridad social.

Los procesos de transición demográfica, sobre todo, en los países del grupo IV (Cuadro 2) dan por resultado que el envejecimiento de la población ante la baja cobertura de los sistemas de previsión social y de pensiones, tenga impacto en las estructuras familiares (SAAD, 2003). La inexistencia de sistemas específicos de protección para adultos mayores dependientes ha dejado a las familias la resolución del problema de la protección y el cuidado de los mayores. En este sentido, "...las familias han asumido la responsabilidad por la asistencia económica y el cuidado de los adultos mayores mientras el Estado y las organizaciones de la sociedad civil han jugado un rol secundario..." (SUNKEL, 2006, p.38).

Los estudios sobre protección y cuidados durante la vejez en América latina Saad (2005), Montes de Oca y Hebrero (2005), Goldani (2004), muestran que los principales apoyos provienen de redes informales, siendo las familiares las más importantes. El principal mecanismo es el de la corresidencia que involucra albergue, comida, tiempo y cuidados para los adultos mayores que, a su vez, pueden participar en el bienestar familiar por medio de efectuar 
aportes mediante la propiedad de la vivienda, ingresos provenientes de rentas o jubilación, o la participación en las actividades domésticas, incluyendo la crianza de los niños (nietos) y el consiguiente efecto facilitador para que las mujeres puedan insertarse laboralmente.

El otro fenómeno que cabe destacar es el "envejecimiento doméstico" definido como la cantidad de hogares con uno o más adultos mayores. CELADE (2008, p.51) indicaba que “... el censo de 2000 en Panamá un $8,9 \%$ de la población tenía 60 o más años, pero un 25,9\% de los hogares particulares tenía uno o más adultos mayores. En todos los países se verifica esta mayor extensión del envejecimiento doméstico, llegando a casi el $35 \%$ en las zonas rurales de Chile. Además, en todos los países, y de manera sistemática en zonas urbanas y rurales, entre el $73 \%$ y el $85 \%$ de los hogares que tiene adultos mayores son liderados precisamente por una persona mayor...".

En este sentido la corresidencia intergeneracional se ha extendido en los últimos años. Esta situación concuerda con la imagen de una cultura familista. Los trabajos empíricos también apuntan en la misma dirección: “...en todos los países analizados más del $70 \%$ de los hogares que tiene adultos mayores corresponde a arreglos multigeneracionales, es decir, a hogares en los que conviven personas de 60 años o más con personas menores de 60 años..." (CELADE, 2008, p.53).

En este sentido, en la provisión de cuidados a los adultos mayores existe un amplio predominio de los vínculos familiares, y dentro de ellos, los filiales por lo que el ámbito de cuidado predominante para los adultos mayores es familiar e intergeneracional.

En relación al envejecimiento doméstico, en el cuadro 6 se puede observar que mientras más avanzada se encuentra la transición demográfica (Uruguay, Argentina y Chile) el envejecimiento doméstico es tres veces superior al demográfico mientras que en una etapa incipiente el envejecimiento doméstico puede llegar a ser casi cinco veces al demográfico (Panamá, Nicaragua y Honduras). Aunque en todos los países predominan los arreglos multigeneracionales, menor proporción se encuentra en Uruguay y Argentina (45,9\% y $46 \%$ respectivamente) por lo que, un aspecto a destacar está relacionado con la forma en que actúan las transferencias intra e intergeneracionales, en especial las que provocan los sistemas de jubilaciones y pensiones ${ }^{10}$ cuyo impacto y universalidad se encuentran más desarrolladas en esos países.

Cuadro 6. América latina (16 países): distribución de los adultos mayores según arreglo residencial, áreas urbanas, 1997 (en porcentajes)

\begin{tabular}{|c|c|c|c|c|c|c|}
\hline & Solo & Con la pareja & $\begin{array}{c}\text { Con otros adultos } \\
\text { mayores }\end{array}$ & Multigeneracionales & $\begin{array}{c}\text { Envejecimiento } \\
\text { doméstico }\end{array}$ & $\begin{array}{c}\text { Envejecimiento } \\
\text { demográfico }\end{array}$ \\
\hline Argentina & 16,7 & 28,6 & 8,7 & 46,0 & 36.6 & 13.3 \\
\hline Bolivia & 11,3 & 15,9 & 4,1 & 68,8 & 21.2 & 6.2 \\
\hline Brasil & 9,9 & 16,3 & 4,3 & 69,5 & 25.7 & 7.9 \\
\hline Chile & 9,7 & 16,9 & 5,9 & 67,5 & 29.3 & 10.2 \\
\hline Colombia & 6,2 & 8,7 & 3,8 & 81,2 & 25.8 & 6.8 \\
\hline Costa Rica & 9,8 & 16,5 & 7,0 & 66,8 & 28.7 & 7.5 \\
\hline Ecuador & 6,3 & 12,0 & 3,1 & 78,5 & 24.0 & 6.9 \\
\hline El Salvador & 8,0 & 8,5 & 4,4 & 79,1 & 31.6 & \\
\hline Honduras & 6,3 & 5,1 & 1,3 & 87,4 & 24.1 & 6.9 \\
\hline México & 8,7 & 13,3 & 3,8 & 74,2 & 20.8 & 6.2 \\
\hline Nicaragua & 5,5 & 7,9 & 3,1 & 83,4 & 24.4 & 6.9 \\
\hline Panamá & 9,8 & 12,8 & 5,2 & 72,2 & 25.8 & 4.8 \\
\hline Paraguay & 7,0 & 13,7 & 2,9 & 76,3 & 22.5 & 8.1 \\
\hline Rep.Dominicana & 7,4 & 7,6 & 2,6 & 82,4 & 23.6 & 5.3 \\
\hline Uruguay & 17,1 & 28,3 & 8,7 & 45,9 & 48.8 & 6.8 \\
\hline Venezuela & 6,4 & 6,9 & 2,6 & 84,1 & 24.7 & 6 \\
\hline
\end{tabular}

Fuente: Elaboración propia sobre datos de Panorama Social 1999-2000, CEPAL. Sobre la base de tabulaciones especiales de las encuestas de hogares de los respectivos países

\footnotetext{
${ }^{10}$ Si bien no existen aún estudios regionales sobre la distribución de adultos mayores según arreglo residencial y quintil de ingresos del grupo doméstico algunos trabajos parciales que apuntan hacia una concentración de éstos en los quintiles más bajos de ingresos.
} 
En esta misma dirección Uthoff et al. (2005) luego de analizar las transferencias intergeneracionales en tres países: Chile, México y El Salvador concluyeron que el monto agregado de dichas transferencias es importante y prácticamente en todos los casos ayudan a suavizar el consumo entre los distintos grupos de edad.

Pero si bien los aportes vía jubilación o pensión de los adultos pueden contribuir al bienestar del hogar hay que considerar la presión sobre las familias para la prestación de servicios de cuidados, sobre todo, en edades avanzadas. Este problema se presenta como un fenómeno en aumento por el incremento de las personas mayores de 75 o de 80 años dentro de la población mayor y que cada vez cuenta con mayor número de población femenina (feminización del envejecimiento) debido a las crecientes diferencias favorables a las mujeres en la esperanza de vida en un contexto en el que, como en América latina, 'la cobertura previsional que brindan los sistemas jubilatorios por lo general es limitada, en el sentido que un alto porcentaje de la población mayor no recibe ingresos por jubilaciones y que, al mismo tiempo, aquellos que las reciben muchas veces no alcanzan ingresos suficientemente altos como para cubrir sus necesidades' (CELADE, 2008, p. 42).

En esta línea argumental, en el cuadro 7, se incorporan datos sobre cobertura de los sistemas previsionales latinoamericanos. En este sentido, entre los cuadros 6 y 7 , se observa que existe una tendencia, en los países que poseen mayor cobertura previsional a que los adultos mayores vivan solos o en pareja y no, en hogares multigeneracionales. Estos datos cobran mayor magnitud, en la medida que se trata de países que, por su avance en el proceso de transición demográfica poseen mayor nivel de envejecimiento.

Cuadro 7. América latina y el Caribe: Transición demográfica y cobertura de los sistemas de pensiones, CIRCA 2000.-

\begin{tabular}{|c|c|c|c|}
\hline $\begin{array}{c}\text { Etapa de la transición } \\
\text { demográfica }\end{array}$ & Países & $\begin{array}{c}\text { Cobertura de pensiones de adultos } \\
\text { mayores }\end{array}$ & $\begin{array}{l}\text { Pensiones } \\
\text { pob. } 65+\end{array}$ \\
\hline \multirow{3}{*}{ Avanzado } & Argentina & Alta & 70,5 \\
\hline & Uruguay & Alta & 85,6 \\
\hline & Chile & Alta & 61,7 \\
\hline \multirow{9}{*}{ Plena } & Brasil & Alta & 85,3 \\
\hline & Colombia & Baja & 25,3 \\
\hline & Costa Rica & Media & 41,3 \\
\hline & Ecuador & Baja & 17,4 \\
\hline & Panamá & Media & 41,7 \\
\hline & México & Baja & 23,3 \\
\hline & Rep. Dominicana & Muy Baja & 11,9 \\
\hline & Venezuela & Baja & 31,3 \\
\hline & Perú & Baja & 27,7 \\
\hline \multirow{5}{*}{ Moderado } & El Salvador & Baja & 16,2 \\
\hline & Guatemala & Baja & 15,4 \\
\hline & Honduras & Muy Baja & 5,3 \\
\hline & Nicaragua & Muy Baja & 0,3 \\
\hline & Paraguay & Muy Baja & 14,9 \\
\hline Incipiente & Bolivia & Baja & 18,0 \\
\hline
\end{tabular}

Fuente: elaboración propia sobre la base Rofman y Lucchetti (2006). Mesa-Lago (2009)

a Alta: más de 50\%; Media: entre 30-50\%; Baja: entre 15-30\%; Muy Baja: menor $15 \%$. 
Si consideramos el grado de envejecimiento doméstico, la mayor magnitud es en Argentina y Uruguay por lo que, dado el grado de desarrollo y cobertura de sus sistemas provisionales y el tipo de arreglo residencial de las personas adultas mayores podemos inferir que, en estos casos, los arreglos multigeneracionales responden a estrategias de los hogares más vulnerables.

De este modo las familias que disponen de recursos acceden a cuidados de calidad sea por la menor tasa de dependencia entre los miembros del hogar o por recurrir al mercado para aprovisionarse del servicio. Los que disponen de menores recursos para acceder a los cuidados mercantiles y que tienen más cargas de cuidado acumulan desventajas por el mayor peso del trabajo doméstico familiar, por las dificultades en el acceso a los escasos servicios públicos o por la necesidad de recurrir a cuidadoras "informales".

Los déficits de cuidado poseen mayor impacto en familias donde las madres trabajadoras - casadas o solteras- no reciben ayuda suficiente de sus parejas o familiares, por lo que, en estos casos, las tensiones se acumulan en las mujeres en un contexto donde la atención que prestan las políticas sociales a la situación de las madres de niños pequeños, de los ancianos, de los enfermos, de los impedidos es insuficiente.

Por lo que y "....contrariando el mandato tradicional de cuidadoras a tiempo completo, en la última década la presencia de las mujeres en los mercados laborales ha aumentado considerablemente: de 3 a entre 4 y 5 de cada diez en tan sólo diez años. El trabajo remunerado es cada vez más asunto de mujeres, aunque el no remunerado -oficio, cuidados, gestión de lo doméstico-, continúa siendo un asunto casi exclusivamente femenino..." (MARTíNEZ FRANZONI, 2007, p.3)

En este sentido, los déficits de cuidados también estarían acumulándose en los sectores de bajos ingresos. En este caso, la salida de las mujeres al mercado de trabajo y el incremento de las demandas reproductivas conducen necesariamente, a una pérdida en la calidad del tiempo y energía dedicada al cuidado. Se puede afirmar que las tensiones entre lo familiar y lo laboral son a la vez causa y efecto de la pobreza y la desigualdad social ya que cuanto mayor sea la cantidad de dependientes mayores serán los gastos familiares. En la misma línea argumental, Pugliese (2004) mostró que la imposición de la "solidaridad familiar"11 para acceder a pensiones de vejez en Uruguay causa tensiones entre los integrantes de los hogares (especialmente a las mujeres cuidadoras de ancianos).

La información del Cuadro 8, continua la línea argumental ya señalada respecto a que una de las estrategias que tienden a desarrollar los hogares de bajos ingresos es la de añadir aportes, no obstante, esta estrategia tiende a incrementar la carga reproductiva del hogar por lo que dificulta la salida de la pobreza ya que existe una relación proporcional entre la carga de cuidados y la probabilidad de que un hogar caiga en la pobreza.

Cuadro 8. Hogares urbanos según tipo, por rango de cantidad de personas que aportan ingresos, cantidad de dependientes e incidencia de la pobreza, 2002. (16 países de América Latina)

\begin{tabular}{|c|c|c|c|c|c|c|c|}
\hline \multirow{2}{*}{ Tipo de familia } & \multicolumn{3}{|c|}{ Cantidad de aportes } & \multicolumn{3}{c|}{ Cantidad de dependientes } & \multirow{2}{*}{$\begin{array}{c}\text { Incidencia de la } \\
\text { pobreza }\end{array}$} \\
\cline { 2 - 7 } & 2 o más & Uno & Ninguno & 2 o más & Uno & Ninguno & 37.4 \\
\hline Compuesta & 73 & 21.2 & 5.8 & 85.6 & 8.1 & 6.3 & 40.9 \\
\hline Extendida & 65.7 & 28.7 & 5.6 & 90.1 & 8.7 & 1.2 & 37.3 \\
\hline Mono-parental jefa mujer & 28.7 & 54.6 & 16.7 & 56.5 & 33.6 & 9.9 & 27.8 \\
\hline Mono-parental jefe hombre & 31.5 & 57.4 & 11.1 & 46.3 & 36.3 & 17.4 & 37.4 \\
\hline Biparental con hijos & 52.2 & 44.4 & 3.4 & 81.6 & 15.8 & 2.6 & 18 \\
\hline Biparental sin hijos & 34.3 & 43.7 & 22 & 22.4 & 39.9 & 37.7 & 25.7 \\
\hline Sin núcleo & 36.4 & 37.6 & 26 & 51.8 & 30.2 & 18 & -6 \\
\hline Unipersonal & - & 60.2 & 39.8 & 40 & 60 & - & 16.6 \\
\hline
\end{tabular}

Fuente: Elaboración propia en base a CEPAL, (2004) sobre datos provenientes de tabulados de Encuestas permanente en hogar de los países.

\footnotetext{
${ }^{11}$ Es decir que, por Ley para acceder a las prestaciones no contributivas se deben computar los ingresos de todos los miembros del hogar y, los mismos no deben superar los tres salarios mínimos. Lo que, como señala el estudio citado, constituye un límite muy bajo para aquellos hogares que han adoptado una estrategia de convivencia en hogares extendidos, que debido al número de integrantes, pueden llegar a superar esa suma.
} 


\section{Conclusiones}

Lo que parece ser un problema propio en los países latinoamericanos es que existe una circularidad entre la escasez de medidas de política familiar y de cuidado y la ausencia de demanda de dichas medidas. El resultado es que las dificultades y los déficits de cuidados no se afrontan a través de la movilización pública sino por medio de las estrategias privadas de las personas y las familias creando una situación por la cual el sistema de desigualdades se reproduce y refuerza.

En los países latinoamericanos, la carga de cuidados que descansa en las familias se conjuga con una política familiar poco desarrollada (ARRAIGADA, 2004) que confía en los recursos privados de familiares y parientes para la provisión de cuidados.

Se produce así un proceso de reforzamiento de las relaciones patriarcales $y$, en general, el reforzamiento de la familia como una institución social central, a pesar del hecho de que ello puede contradecir abiertamente las declaraciones oficiales políticamente correctas sobre la igualdad de oportunidades para ambos sexos.

En términos generales, pareciera existir una situación de equilibrio funcional en la que la participación femenina en el mercado laboral y la fecundidad en los sectores más vulnerables se refuerzan mutuamente. La existencia de redes familiares cimentadas en el intercambio de ayuda ha inhibido la externalización de los servicios femeninos intensivos de trabajo y evitado el incremento de demandas hacia el sector público para que fomente la oferta de empleo mediante la creación de puestos de trabajo en servicios de cuidados.

Como se ha indicado, en condiciones de pobreza se registra una tendencia hacia el incremento del tipo de familia extendida y recompuesta a medida que se observa el aumento en el total de aportes. Esto no se traduce, necesariamente, en un reforzamiento de los vínculos parentales ni de solidaridad destinados al cuidado de los dependientes. De hecho, se ha establecido que se incrementan las dificultades para la salida de la pobreza conforme aumenta el tamaño del hogar por adulto equivalente (MARCHIONI; GASPARINI, 2002; CARBALLO, 2004) de allí que, si bien, las estrategias de incorporar aportan (efecto trabajador adicional), pueden ser efectivas para evitar la indigencia y terminan siendo, a largo plazo, un obstáculo para la salida de la pobreza.

En una población cuya capacidad de acceso a niveles de bienestar se modifica principalmente a través de dos mecanismos: incrementando la cantidad de miembros al interior del hogar que perciben ingresos, que incluye la participación laboral de mujeres adultas y adolescentes varones, o por la incorporación al hogar de otra persona que genere ingresos; y dos, por la reducción de las cargas reproductivas y de cuidado del hogar, que significa la salida de alguno de sus miembros dependientes las actividades de cuidado tienden a recaer sobre las mujeres por lo que la carga de cuidados no se distribuye hacia el interior del hogar, sino que recae en las mujeres adultas o las hijas adolescentes.

Si un régimen de bienestar se desarrolla a partir de tres dimensiones, a saber: a- por un padrón dado de previsión social entendida como “... el modo combinado e interdependiente como el bienestar producido y distribuido entre el estado, el mercado y la familia" (ESPING-ANDERSEN, 1999, p.35). Al que, se le ha adicionado un cuarto componente, genéricamente referido como "tercer sector" (o el sector voluntario, o la comunidad o las organizaciones de la "sociedad civil"); b- por la estructura del sistema público de políticas sociales (GOUGH, 1999), conformado por los programas de seguridad social, servicios educacionales y de salud (más o menos universales), programas de asistencia social y (eventuales) transferencias monetarias a grupos sociales determinados; $y$, finalmente, por un tipo predominante de familia según características de la estructura familiar de poder y de la división sexual de trabajo prevaleciente (SAINSBURY, 1999). El resultado de estas combinaciones y de las instituciones en que operan, da lugar a ciertos grados de independencia o autonomía del bienestar de las familias y personas en relación al mercado de trabajo (de-commodification) ${ }^{12}$ y en relación a los sistemas domésticos de

\footnotetext{
${ }^{12}$ Otra cara del derecho social de la ciudadanía, la desmercatilización significa el grado en que el Estado de bienestar debilita el vínculo monetario, garantizando el derecho independientemente de la participación en el mercado (ESPING-ANDERSEN, 1999, p.43).
} 
cuidados y protección (de-familiarisation) ${ }^{13}$ (ESPING-ANDERSEN, 1999).

En América latina el régimen de bienestar podría ser caracterizado como 'familista' debido a que combina con un sistema de protección social basado en la idea de hombre proveedor cuya centralidad es la familia entendida como protectora y responsable de brindar cuidado y bienestar a sus miembros por lo que asume que la familia se encuentra en condiciones de llevar adelante las funciones relacionadas al cuidado.

Sin embargo, los procesos estudiados nos obligan a repensar esta afirmación ya que, si los niveles de bienestar y las políticas de cuidado de la población vulnerable dependen de las disposiciones y relaciones familiares antes de las medidas desplegadas por las instituciones públicas, esto nos conduciría hacia dos procesos divergentes que, al mismo tiempo, tenderían a consolidar la cohesión de la familia en los sectores más vulnerables.

En este sentido, los déficits no tendrían que ser interpretados como resultado de un bajo nivel de desmercantilización y sí de desfamiliarización, ya que coloca el peso de la responsabilidad del bienestar sobre los hogares como resultado de un sistema donde las mujeres casadas, no tienen directamente acceso a las transferencias monetarias ${ }^{14} \mathrm{ni}$ al aprovisionamiento público de servicios de cuidado por lo que genera una situación de dependencia mutua de hombres y mujeres, en la cual los primeros se encargan de aportar los ingresos y las segundas de los servicios de cuidados.

\footnotetext{
13 Desfamiliarización expresa el grado de reducción de la dependencia del individuo respecto de la familia o, inversamente, el aumento de la capacidad de comando del individuo sobre recursos económicos, independientemente de las reciprocidades familiares o conyugales (ESPING-ANDERSEN, 1999, p.45).

14 Me refiero a los programas de transferencias condicionadas y a los criterios de exclusión que los sustentan (DEL VALLE, 2010). Al respecto la conclusión a la que arriba González de la Rocha al analizar el Programa oportunidades es gráfica: “..."el éxito de Oportunidades (...), se ha fincado, entre otros factores, en la participación de millones de mujeres sobrecargadas de trabajo. Oportunidades es un programa social que opera con una noción tradicional de familia donde la mujer es vista como proveedora de servicios domésticos y reproductivos y que, por lo tanto, puede dedicar su tiempo y su esfuerzo a las corresponsabilidades que el Programa Oportunidades exige como condición. El caso de Oportunidades, (...) nos muestra la asociación que - en el campo de las ideas que nutren la política social - sigue existiendo entre los intereses y necesidades de las familias con aquellos de las mujeres" (GONZÁLEZ DE LA ROCHA, 2005, p.247).
}

En este sentido, se tendría que hablar de un sistema de cuidados dual, mercantilizado para los estratos medios y altos y, familiarizados para los sectores vulnerables. Éste sistema tiene que ser interpretado como una consecuencia de la interacción entre el proceso de transición demográfica, las características socioeconómicas de las familias y el funcionamiento de un sistema de familia y parentesco basados en vínculos intergeneracionales y redes de solidaridad como medio de garantizar apoyo y cuidados a los individuos.

En los países latinoamericanos podríamos hablar de un modelo de política de cuidado a medida que este es implícito, en el sentido en que constituye el resultado de respuestas en gran parte descoordinadas de los dispositivos de intervención del Estado en diversos campos de la política social, partiendo del supuesto de que la familia debe proveerse cuidados a sí misma y a sus miembros y que, en todo caso, las políticas públicas están destinadas a fomentar la solidaridad entre parientes.

A diferencia de la atención sanitaria o de la educación, que han sido definidas como una prioridad regional y en que hubo una fuerte voluntad política para comenzar a ampliar la cobertura, la problemática del cuidado todavía no ha hallado su camino hasta la agenda política.

El problema y las políticas del cuidado se encuentran vinculadas, como sostiene Goldani "...la noción de familia que manejan los diversos programas sociales. Esta continúa siendo de un tipo fijo, y muchas veces idealizado, de familia nuclear, aunque otras veces, al tratarse de programas para individuos en las familias (el joven, el anciano, la mujer), se reconocen las diferencias e inequidades al interior de la familia" (GOLDANI, 2005, p.327). A su vez, las nuevas demandas de cuidados no se adaptan a la noción ni a las capacidades que presentan las actuales relaciones familiares, de allí que "...las estructuras familiares han levantado una serie de demandas y requerimientos que por la rigidez de las definiciones de familia las políticas públicas no han podido integrar (GOLDANI, 2005, p.327).

Para ello, tendríamos que comenzar a pensar en una política pública orientada 'para el cuidado' que vuelva a articular la relación entre mercado, trabajo doméstico y provisión de bienestar por parte del Estado y que tendrá 
que poner en consideración el surgimiento de nuevos y variados tipos de arreglos familiares; la redefinición del cuidado a partir de una redistribución equitativa de las responsabilidades reproductivas y, una redefinición de las funciones reproductivas que sea coherente con la idea de equidad de género ya que, mientras toda la responsabilidad del cuidado recaiga en la mujer se acaba homologando la familia a la mujer y queda al descubierto la ausencia de una visión integral respecto de todos los miembros de la familia. En suma, el problema del cuidado se vincula con cuestiones normativas, es decir, con la forma de salvaguardar la igualdad de acceso a los cuidados y a su universalidad por lo que implica poner en juego algún modelo de justicia social que funcione desfamiliarizando al Estado, al mercado y a las familias bajo la premisa de asegurar derechos a todos los ciudadanos.

\section{Bibliografía}

ARRAIGADA, Irma. Políticas públicas y de género: una relación difícil en Revista Paraguaya de Sociología, Año 35, n.101, 1999.

ARRAIGADA, Irma. Los límites del uso del tiempo: dificultades para las políticas de conciliación familia y trabajo. Reunión de Expertos Políticas hacia las Familias, Protección e Inclusión Sociales, Santiago de Chile, CEPAL, 28-29 de junio, 2005.

ARRIAGADA, Irma. Familias latinoamericanas. diagnóstico y políticas públicas en los inicios del nuevo siglo. Santiago de Chile, CEPAL, División de Desarrollo Social, Serie Políticas Sociales, n. 57, 2001.

ARRIAGADA, Irma. Cambios y continuidades en las familias latinoamericanas. Efectos del descenso de la fecundidad en La fecundidad en América Latina: ¿Transición o revolución? Serie Seminarios y Conferencias n. 36, CELADE, 2004.

ARRIAGADA, Irma. “¿Existen políticas innovadoras hacia las familias latinoamericanas?" en Papeles de Población, Centro de Investigación y Estudios Avanzados de la Población, UAEM, Nueva Época, Año 11, n. 43, 2005. México.

ARRIAGADA, Irma. (Comp.). Familias y políticas públicas en América Latina: una historia de desencuentros. Libros de la CEPAL, n. 96 (LC/G.2345-P), Santiago de Chile, Comisión Económica para América Latina y el Caribe (CEPAL). Publicación de las Naciones Unidas, n. de venta: S.07.II.G.97, 2007.
BATTHYÁNY, Karina. Género y cuidados familiares ¿Quién se hace cargo del cuidado y atención de los niños y adultos mayores? En: Fassler Clara (Coord.). Familias en cambio en un mundo en cambio. Montevideo: Trilce. Red Género y Familia, 2006.

BATTHYÁNY, Karina. Género y cuidados familiares ¿Quién se hace cargo del cuidado y atención de los niños y adultos mayores en Montevideo? Proyecto de Investigación I+D, CSIC UDELAR, Facultad de Ciencias Sociales, Departamento de Sociología, Apoyo: UNFPA Uruguay, 2007. Disponible en: <http:// www.unfpa.org.uy/userfiles/informacion/items/210_ pdf.pdf>. Consulta: 8 agosto 2010.

BID/CEPAL/CELADE, La transición demográfica en América Latina. Actualizado con datos Boletín Demográfico n.62, CELADE, 1998. Santiago de Chile.

BUBECK, Diemut E. Care, gender and justice. Oxford: Clarendon Press, 1995.

CARBALLO, Jorge Características del hogar y salida de la pobreza: un análisis de los hogares urbanos para el período postconvertibilidad, Departamento de Economia, Finanzas y de Estadística y Matemática, Fac. de Cs. Económicas, Univ. Nacional de Córdoba, Argentina, 2004

CELADE. Tendencias demográficas y protección social en América Latina y el Caribe. Programa Regional de Población y Desarrollo Centro Latinoamericano y Caribeño de Demografía (CELADE)-División de Población/ Fondo de Población de las Naciones Unidas, Santiago de Chile, febrero de 2008.

Centro latinoamericano y caribeño de Demografía. Proyecciones de población vigentes: Naciones Unidas. In: UNITED NATIONS. World populations prospects: the 1992 revision. New York: United Nations, 1992.

CEPAL Comisión Económica para América Latina. Panorama social de América Latina 1999-2000. Publicación de las Naciones Unidas, Santiago de Chile, 2000.

Comisión Económica para América Latina. Panorama social de América Latina, 2004 (LC/ L.2220-P/E). Publicación de las Naciones Unidas, Santiago de Chile, 2004.

Comisión Económica para América Latina. El aporte de las mujeres a la igualdad en América Latina y el Caribe (LC/L.2738). (CRM.10/3)/Rev.1), Santiago de Chile, 2007a. 
Comisión Económica para América Latina. Panorama social de América Latina, 2007 (LC/ G.2351-P). Publicación de las Naciones Unidas, Santiago de Chile, 2008.

Comisión Económica para América Latina. Panorama social de América Latina, 2008 (LC/ G.2402-P). Publicación de las Naciones Unidas, Santiago de Chile, 2009.

. Comisión Económica para América Latina. La reacción de los gobiernos de las Américas frente a la crisis internacional: una presentación sintética de las medidas de política anunciadas hasta el 30 de septiembre de 2009. (LC/L.3025/Rev.5), Santiago de Chile, octubre, 2009a.

CHESNAIS, J. C. La transition demographique: etapes, forms, implications economiques. PUF, Paris, 1986.

DEL VALLE, Alejandro. Regímenes de bienestar relaciones entre el caso asiático y la realidad latinoamericana, en nómadas. Revista Crítica de Ciencias Sociales y Jurídicas, n.19, Julio-Diciembre, Universidad Complutense de Madrid- España, p.2048, 2008.

Transferencias condicionadas, redes de protección social y Bienestar en Latinoamérica. Kairos Revista de Temas Sociales, n.24, p. 8-29, 2009. Universidad Nacional de San Luis, San Luis, Argentina.

. Comparing welfare regimes in Latin America. European Review of Latin American and Caribbean Studies, n.88, January-June, p. 21-36, 2010. Centre for Latin American Research and Documentation, Amsterdam, The Netherlands.

Reformas estructurales, Mercado de trabajo y Protección social en América latina, en Portularia. Revista de Trabajo Social, n. 1, v.10, p. 3-21, 2010a. Departamento de Trabajo Social y Sociología, Universidad de Huelva, España.

DRAIBE, Sônia; RIESCO, Manuel. El Estado de bienestar en América Latina desde una perspectiva histórica y conceptual: avance de consultoría en proceso para la Unidad de desarrollo social. Sede Subregional de la CEPAL en Ciudad de México, 2005.

ESPING-ANDERSEN, Gosta. Social foundations of postindustrial economies. Nueva York: Oxford Press, 1999.

GILLIGAN, C. In a different voice: psychological theory and women's development. Cambridge, MA: Harvard University Press, 1982.
GOLDANI, Ana Maria. Contratos intergeracionais e reconstrução do estado de bem-estar: por que se deve repensar essa relação para o Brasil?", En: CAMARANO, A. A., (Org.). Os novos idosos brasileiros: muito além dos 60 ? Capitulo 7 , Rio de Janeiro, IPEA, 2004.

GOLDANI, Ana María. Reinventar políticas para familias reinventadas: entre la 'realidad' brasileña y la 'utopía'. En: ARRIAGADA, Irma. (Ed.). Políticas hacia las familias, protección e inclusión social. Serie Seminarios y Conferencias, n.46, División de Desarrollo Social, CEPAL, Santiago, 2005.

GONZALEZ DE LA ROCHA, Mercedes. Familias y politica social en Mexico: el caso de oportunidades. Serie Seminarios y conferencias 46. CEPAL, Santiago, Chile, 2005. Disponible en: <http://www.eclac.cl/dds/ noticias/paginas/2/21682/Mercedes_GdelaRocha. pdf>. Consulta: 8 agosto 2009.

GOUGH, lan. Welfare regimes: on adapting the framework to developing countries. Global Social Policy Program. Working Paper 1. University of Bath, 1999. <http://www.bath.ac.uk/Faculties/HumSocSci/ IFIPA/GSP/>. Consulta: 8 agosto 2009.

MARCHIONI, Mariana; GASPARINI, Leonardo. Características demográficas y pobreza en la Argentina. Buenos Aires, Banco Interamericano de Desarrollo, 2002.

MARTÍNEZ FRANZONI, Juliana. Regímenes del bienestar en América Latina. Documento de trabajo n.11, Fundación Carolina, España, 2007.

MESA-LAGO, Carmelo. Efectos de la crisis global sobre la seguridad social de salud y pensiones en América Latina y el Caribe y recomendaciones de política. Serie Políticas sociales, n. 150 (LC/ L.3104-P), CEPAL, Santiago de Chile, octubre, 2009.

MONTES DE OCA, Verónica; HEBRERO, M. México y estado de Guanajuato: transferencias intergeneracionales hacia los adultos mayores, en Notas de Población, CELADE-División de Población CEPAL, n. 80, año XXXII, octubre, 2005.

MURILLO, Soledad. Cara y cruz del cuidado que donan las mujeres. Congreso Internacional Cuidar cuesta: costes y beneficios del cuidado, SARE. Emakunde, Bilbao, 2003.

ORGANIZACIÓN INTERNACIONAL DEL TRABAJO. Programa de las Naciones Unidas para el Desarrollo -OIT/PNUD. Trabajo y familia: hacia nuevas formas de conciliación con corresponsabilidad social. Santiago de Chile, 2009. 
PUGLIESE, Leticia Programas no contributivos en la Seguridad Social Uruguaya. Tesis de Maestría en Sociología, Universidad de la República, Montevideo, 2004.

RODRÍGUEZ VIGNOLI, Jorge. Cohabitación en América Latina: ¿Modernidad, exclusión o diversidad? Papeles de Población, v.40, p.97-145, 2004.

ROFMAN, Rafael; LEONARDO, Lucchetti. Pension systems in Latin America: concepts and measurements of coverage. Social Protection Discussion Paper, n. 0616, World Bank, 2006.

SAAD, Pablo. Transferencias informales de apoyo de los adultos mayores en América Latina y el Caribe: estudio comparativo de las encuestas SABE. Notas de Población. Número Especial "Redes de apoyo social de las personas mayores", Celade, CEPAL, 2003.

Arreglos residenciales y transferencias de apoyo informal de los adultos mayores en América Latina y el Caribe. Documento presentado al Taller sobre Transformaciones demográficas, transferencias intergeneracionales y protección social en América Latina, Santiago de Chile, 6 y 7 de julio, 2005.

SAINSBURY, Diane. Gender and social-democratic welfare state. In: SAINSBURY, Diane (Ed.). Gender and welfare state regimes. Oxford: Oxford Univ. Press, 1999.

SCHKOLNIK, Mariana. Tensión entre familia y trabajo. En: ARRIAGADA, I.; ARANDA, V. (Comp.). Cambio de las familias en el marco de las transformaciones globales: necesidad de políticas públicas eficaces. Serie Seminarios y Conferencias, DDS. Santiago: CEPAL, 2004.

SIIM, Birte. The ccandinavian welfare states: towards sexual equality or a new kind of male dominance. Acta Sociologica, v.30, n.3-4, p.255-270, 1987.

SUNKEL, Guillermo. El papel de la familia en la protección social en América Latina. Serie Políticas sociales, n. 120 (LC/L.2530-P/E), Santiago de Chile, Comisión Económica para América Latina y el Caribe (CEPAL), 2006.

TITMUSS, Richard M. Social policy: an introduction. London: Allen and Unwin, 1974.

UTHOFF, Andras; JORGE, Bravo; CECILIA, Vera; NORA, Ruedi. Cambios en la estructura por edades de la población, transferencias, intergeneracionales y protección social en América Latina. CEPAL, 2005.
UTHOFF, Andras; VERA, Cecilia; RUEDI, Nora. Relación de dependencia del trabajo formal y brechas de protección social en América Latina y el Caribe. Serie Financiamiento del desarrollo, n. 169, LC/L.2497-P, Santiago de Chile, Comisión Económica para América Latina y el Caribe (CEPAL), febrero, 2006. 